\title{
Deficient go, no-go brightness discrimination in rats following hippocampal lesions*
}

\author{
MICHAEL L. WOODRUFF† \\ University of Florida, Gainesville, Florida 32601 \\ LARRY W. MEANS \\ East Carolina University, Greenville, North Carolina 27834 \\ and \\ ROBERT L. ISAACSON \\ University of Florida, Gainesville, Florida 32601
}

\begin{abstract}
Hippocampally ablated, cortically damaged, and intact control rats were trained postoperatively on a discrete-trial, go, no-go brightness discrimination task in an operant situation. The hippocampally ablated animals were found to be deficient on acquisition primarily due to inappropriate responding on no-go (nonreinforced) trials. The deficit is consistent with other operant brightness discrimination studies, but contrasts with the facilitated go, no-go alternation performance exhibited by hippocampally damaged rats.
\end{abstract}

Several studies have shown that hippocampally lesioned rats are facilitated on go, no-go single-alternation acquisition (Means, Walker, \& Isaacson, 1970; Walker, Means, \& Isaacson, 1970; Walker, Messer, Freund, \& Means, 1972). A similar observation has also been made in cats (Brown, Kaufman, \& Marco, 1969). On the other hand, rats with hippocampal lesions are impaired in acquiring a visual discrimination in an operant situation (Niki, 1965; Woodruff \& Isaacson, 1972; Woodruff, Schneiderman, \& Isaacson, 1972). Also, cats with hippocampal lesions have been found to be deficient on an operant discrimination where go and no-go trials are signaled by a tone or a light (Buerger, 1970).

The present study was undertaken to study the behavior of hippocampally damaged rats in an experimental paradigm similar to that used in the go, no-go alternation studies, but which also required the rats to acquire a visual discrimination. From the alternation studies, facilitated acquisition might be predicted; from the discrimination studies, a deficit would be predicted.

\section{METHOD}

\section{Subjects}

Twenty-two male hooded rats, weighing between 370 and

*This research was supported in part by NIMH Grant 16384-03 to R. L. Isaacson and by USPHS Training Grant $\mathrm{MH}-10320$ to the Center for Neurobiological Sciences, University of Florida. The authors wish to thank Mrs. Pauletta Sanders for her excellent histological work and Mr. David Clampitt for his assistance with the behavioral testing.

$\dagger$ Requests for reprints should be sent to Michael L. Woodruff, Department of Psychology, University of Florida, Gainesville, Florida 32601.
$487 \mathrm{~g}$ at the time of surgery, were employed as Ss. Seven rats received bilateral aspiration lesions of the hippocampus and overlying cortex (Group $\mathrm{H}$ ), seven received bilateral lesions of only the overlying cortex (Group C), and eight served as unoperated controls (Group N). The surgical procedures were essentially the same as those reported by Isaacson, Douglas, and Moore (1961). Following surgery, the animals were allowed to recover for 10-18 days and then placed on a food-deprivation schedule such that they were maintained at $85 \%$ of their preoperative ad lib weight. All rats were fed after their daily conditioning session.

\section{Procedure}

All behavioral testing was conducted in two Grason-Stadler test chambers (Model E31225-3100), each enclosed in a sound-attenuating chamber. The chambers contained two levers, only one of which was used in the present study, and a stimulus light above each lever.

Upon reaching deprivation weight, all animals were given magazine and CRF training employing the same procedures used by Means et al (1970). Each rat was given one magazine training session followed by daily 10-min CRF sessions until 275 reinforced responses were accumulated. The stimulus conditions of magazine and CRF training matched the stimulus conditions of the reinforced trials of the discrimination problem, namely, both the houselight and the cue light over the lever were illuminated.

Go, no-go discrimination training was initiated on the session following completion of CRF training. Each session consisted of 10 reinforced (go) and 10 nonreinforced (no-go) trials that occurred in random order. Each trial consisted of a 20-sec illumination of the chamber by the houselight and was followed by a 10-sec ITI during which the houselight was off. On all go trials, the cue light over the lever was illuminated and all barpresses were reinforced on a CRF schedule. Barpresses occurring during either the no-go trials or the ITI were not reinforced. The dependent variables were the latency to the first press and the total number of presses on each trial. A latency ratio, defined as (the latency to the first response on go trials)/(the latency to first response on no-go trials), and a response ratio, defined as (the total responses on no-go trials)/(the total responses on go trials), were determined for each $S$ on each session. Note that each ratio was defined such 

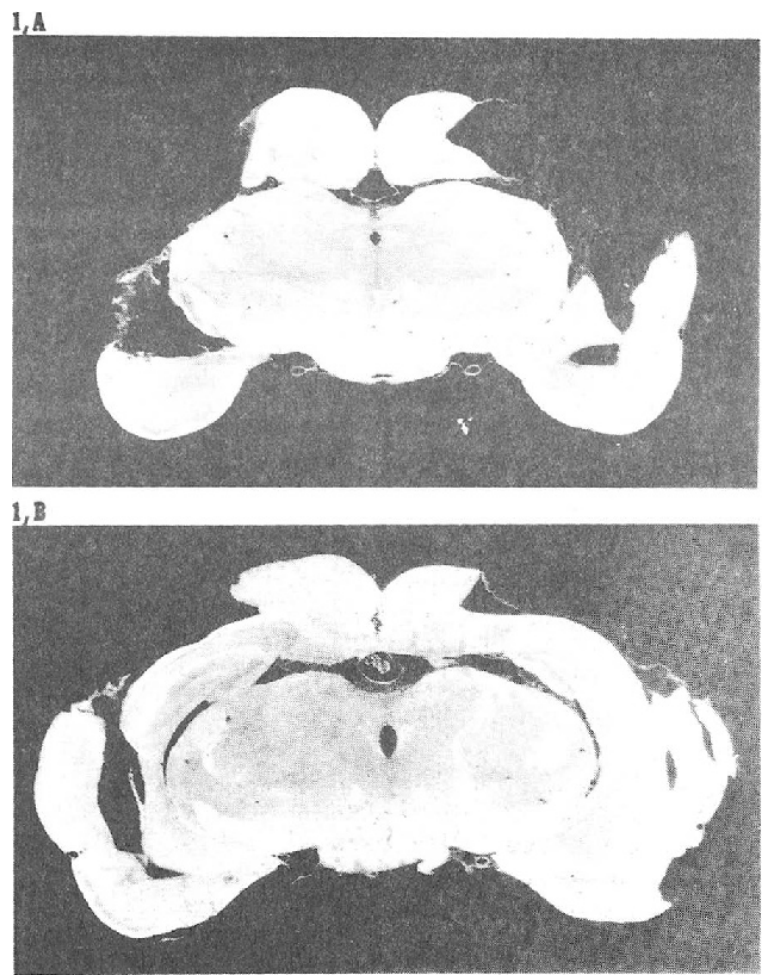

Fig. 1. Representative hippocampal (A) and cortical (B) lesions.

that a decrease in value indicates an improvement in performance. All rats were trained to a criterion of three consecutive sessions on which both the latency and response ratios were less than .50 or until they had received 50 sessions (1,000 trials), whichever occurred first. During the first few sessions of discrimination training, it was noted that one or two rats in each group were pressing fewer than six times in a session. These animals were then given discrete-trial CRF training, where the cue light was illumianted on all trials and all trial responses were reinforced until they began to respond consistently. All the CRF training sessions and the discrimination sessions on which fewer than six total responses occurred were not counted in the number of sessions to criterion. It was reasoned that animals not responding were receiving no information relevant to the discrimination problem.

At the conclusion of behavioral testing, all operated Ss were sacrificed with an overdose of Nembutal and intracardially perfused with $0.9 \%$ saline followed by $10 \%$ formalin. The brains were removed, sectioned at 30 microns, and every 10 th section was retained, mounted on a slide, and stained with thionin.

\section{RESULTS}

\section{Histology}

Figure 1 presents representative hippocampal and cortical lesions. Examination of the hippocampal lesions revealed that the middle one-third and much of the ventral hippocampus was destroyed in all animals in Group $\mathrm{H}$; while portions of the dorsal hippocampus remained intact (Fig. 1A). Also, all rats in Group H sustained extensive damage to the posterolateral cortex, complete section of the fimbria, and damage to the corpus callosum. Four of the six rats in Group $\mathrm{H}$ also showed evidence of degeneration in the lateral geniculate. Three had unilateral damage to the entorhinal cortex. In addition, one hippocampally damaged rat exhibited extensive unilateral thalamic damage and was excluded from further analysis, although behaviorally this animal was not distinguishable from the other rats in the group.

The cortical control lesions typically involved slightly less cortex than did the hippocampal lesions (Fig. 1B). One animal had slight bilateral damage to the surface of the hippocampus, and four of the seven cortically lesioned Ss demonstrated degeneration in the lateral geniculate nucleus.

\section{Behavioral Results}

The mean and median number of sessions to the latency-response criterion for each group are shown in Table 1. Four of six in Group $\mathrm{H}$ failed to attain criterion in 50 sessions, while all animals in the other two groups reached criterion. A Kruskal-Wallis analysis of variance revealed that the three groups differed significantly $(p<.001)$ on sessions to criterion. Subsequent Mann-Whitney tests revealed that Group $\mathrm{H}$ required more sessions than either Group $\mathrm{C}(\mathrm{p}<.026)$ or Group N $(p<.001)$, and that the latter two groups did not differ from one another $(p<.06)$.

In an effort to further examine acquisition, the three groups were compared on a criterion based only on response latency, i.e., the total number of sessions required to attain a latency ratio of less than .50 on three consecutive sessions (see Table 1). A Kruskal-Wallis analysis revealed that the three groups differed significantly $(p<.02)$, and subsequent Mann-Whitney tests revealed that Group $\mathrm{H}$ required significantly more sessions to reach criterion than did Group N $(p<.002)$ and that Group $\mathrm{C}$ did not differ from either Group $\mathrm{H}$ $(p<.07)$ or Group $N(p<.10)$. Finally, a comparison of

Table 1

Number of Sessions to Latency, Response, and Combined Latency-Response Acquisition Criteria

\begin{tabular}{clccc}
\hline & & \multicolumn{3}{c}{ Criteria } \\
\cline { 3 - 5 } Group & Statistic & $\begin{array}{l}\text { Latency- } \\
\text { Response }\end{array}$ & $\begin{array}{c}\text { Re- } \\
\text { sponse }\end{array}$ & Latency \\
\hline \multirow{2}{*}{ Hippocampal } & Mean & 42.7 & 22.5 & 37.8 \\
& Median & 50 & 21.5 & 33.5 \\
Cortical & Mean & 29.0 & 16.8 & 27.3 \\
& Median & 24 & 14 & 25 \\
Normal & Mean & 19.1 & 13.5 & 18.4 \\
& Median & 16.5 & 12 & 16.5 \\
\hline
\end{tabular}

Note-Sessions during which six or fewer barpresses occurred are not included in the number of sessions to the various criteria. Brackets connect groups which differ significantly from each other $(p<.05$ in all cases). 
the three groups on the number of sessions needed to achieve a response ratio of less than .50 on 3 consecutive days produced no significant differences. Thus, the three acquisition analyses reveal that the hippocampal deficit was due largely to their inability to acquire a latency ratio of less than .50 .

Since the latency ratio is dependent on both go and no-go trial latencies, the three groups were compared on their mean go and their no-go latencies on the last three sessions, which were criterion sessions for all animals reaching criterion. The mean go and no-go latencies expressed in seconds and the mean number of responses made on go and no-go criterion trials are shown in Table 2. Group $\mathrm{H}$ tended to have a shorter barpress latency than the other two groups on both go and no-go trials; however, the difference between these two types of trials was significant only for the no-go latencies, as determined by a Kruskal-Wallis analysis of variance and subsequent Mann-Whitney tests ( $p<.002$ in all cases). Thus, the analysis suggests that the latency ratio criterion deficit was primarily due to hippocampal animals' relative inability to withhold making the first response on no-go trials. A similar analysis of the number of responses made on go and no-go trials on criterion sessions produced much the same results as the latency analysis (Table 2). Animals in Group $\mathrm{H}$ made significantly more presses on no-go trials than animals in either Group C or Group N ( $p<.01$ in both cases). Thus, the latency and response data suggest that Group $\mathrm{H}$ animals did not inhibit responding on no-go trials as effectively as the control animals.

Unlike earlier go, no-go studies (Means et al, 1970; Walker et al, 1972), the lever was available to the rats during the ITI in the present study. A comparison of the three groups on number of ITI responses made during the three criterion sessions revealed that Groups $\mathrm{H}, \mathrm{C}$, and $\mathrm{N}$ had session means of 40.8, 9.1, and 9.3, respectively. A Kruskal-Wallis analysis of variance resulted in a significant effect $(\mathrm{p}<.01)$, and subsequent Mann-Whitney tests revealed that Group $\mathrm{H}$ responded significantly more frequently during the ITIs than did either Group C or Group N ( $p<.01$ in both cases), which did not differ from each other.

Finally, since in the present task brightness was used as the discriminative stimulus, the Group $\mathrm{H}$ and Group $\mathrm{C}$ animals evidencing lateral geniculate degeneration were compared with no lateral geniculate damage. The four hippocampally lesioned rats with geniculate damage required $25,31,50$, and 50 trials to attain the latency-response criterion, while the two animals evidencing no degeneration in the geniculates required 50 trials each to attain criterion. The four cortically lesioned rats with degeneration in the lateral geniculate required $23,16,47$, and 15 trials to criterion, while the three animals with no degeneration required 24,29 , and 49 trials to criterion. Thus, the data do not suggest that the deficit was due to the damage to the visual system.
Table 2

Mean Latency and Mean Number of Responses on Go and No-Go Criterion Sessions for the Three Groups

\begin{tabular}{|c|c|c|c|c|}
\hline \multirow[b]{2}{*}{ Group } & \multicolumn{2}{|c|}{ Latency } & \multicolumn{2}{|c|}{ Responses } \\
\hline & Go & $\mathrm{No}+\mathrm{Go}$ & Go & No-Go \\
\hline Hippocampal & 2.2 & 5.277 & 74.3 & 39.677 \\
\hline Cortical & 4.0 & ] & 65.6 & $12.3 \mathrm{~J}$ \\
\hline Normal & 4.4 & 14.2 & 61.2 & 10.6 \\
\hline
\end{tabular}

Note-Brackets connect groups which differ from each other at .01 level of significance.

\section{DISCUSSION}

The results show that the hippocampally damaged rats were deficient on go, no-go brightness discrimination acquisition. Further, the elevated rate of responding during the no-go trials and the ITIs reveals that the deficit of the animals with hippocampal destruction was related to a failure to suppress responses at the appropriate time. The present results support the specific observation that rats with hippocampal lesions are deficient on barpress brightness discrimination tasks (Niki, 1965; Woodruff \& Isaacson, 1972; Woodruff et al, 1972). The deficit occurred in a general experimental paradigm in which animals with hippocampal lesions are facilitated, i.e., a go, no-go alternation barpress task (Means et al, 1970; Walker et al, 1970). Trial and ITI duration, reinforcement, deprivation, trials per day, strain of rat, and brain lesions were the same in this discrimination task and in the go, no-go alternation task. However, two differences in experimental design did exist. In the alternation study, go and no-go trials occurred alternately and were accompanied by a light as a redundant external cue, whereas in the discrimination task, go and no-go trials occurred randomly and the light was the only cue for a correct response. Levers were available for responding during the ITI in the present discrimination study, but not in the previously published go, no-go studies. Recent observations ${ }^{1}$ indicate that the availability of the lever during the ITI does not change the rate of acquisition of the go, no-go problem. Therefore, it appears that the critical difference in the performance of the animals is in the nature of the cue which could be used to solve the problem.

From the present results, it can be concluded that the light used as a redundant cue in the go, no-go alternation studies cited previously was not important to the animals in performing the alternation task. This supposition is further supported by the finding of Walker et al (1970) that the introduction and removal of a cue light did not change the performance of hippocampally ablated or control rats in the task. It would seem that hippocampally ablated rats make good use of whatever internal cues are available in performance of the single alternation task and are not affected by the presence or absence of a cue light. 
Hippocampal damage appears to facilitate acquisition of go, no-go alternation tasks, but seems to impair the use of visual signals in an operant situation. It is to be noted that the results reported here and those obtained by Woodruff and Isaacson (1972) should not be interpreted to mean that animals with hippocampal lesions are incapable of using visual cues to guide behavior, as several studies employing mazes report that hippocampally damaged rats show no deficit in the acquisition of a brightness discrimination in this situation (Kimble, 1963; Rabe, 1963; Silveira \& Kimble, 1968). Hippocampally lesioned animals are less distracted than controls by the introduction of novel stimuli which have a visual component (Wickelgren \& Isaacson, 1963; Raphelson et al, 1965). Ireland and Isaacson (1968) found that low-intensity visual or auditory stimulation produced a diminished behavioral reaction while more intense stimulation produced exaggerated reactions in hippocampally damaged gerbils. It is likely, therefore, that the intensity of stimulation is of critical importance for the lesioned Ss, and, though the hippocampally lesioned animals failed to use the visual signals of the operant chamber, they may have been able to do so if the lights had been more intense, had flickered, been in different positions, or in some other way been more attention-provoking. Means and Walker ${ }^{2}$ have found that a loud auditory signal can be used by animals with hippocampal lesions in an operant discriminative paradigm in which go, no-go trials are presented randomly. It remains to be seen whether or not a visual signal of greater intensity would allow the lesioned animals to perform more successfully.

It is interesting that the performance of animals with lesions restricted to neocortex is different in the go, no-go alternation and go, no-go brightness discrimination problems. In the alternation studies (Means et al, 1970; Walker et al, 1972), cortically lesioned rats were deficient on the acquisition of the alternation task. However, in the present brightness discrimination task, the cortically damaged animals did not significantly differ from the normals on either the response or the latency ratios. It is perhaps of greater interest that the debility imposed by the cortical lesion in the go, no-go alternation task is not found in the animals with hippocampal lesions imposed upon the neocortical destruction.

\section{REFERENCES}

Brown, T. S., Kaufman, P. G., \& Marco, L. A. The hippocampus and response preservation in the cat. Brain Research, 1969, $12,86-98$.
Buerger, A. A. Effects of preoperative training on relearning a successive discrimination by cats with hippocampal lesions. Journal of Comparative \& Physiological Psychology, 1970, 72, $462-466$.

Ireland, L., \& Isaacson, R. L. Reactivity in the hippocampectomized gerbil. Psychonomic Science, 1968, 12, 163-164.

Isaacson, R. L., Douglas, R. S., \& Moore, R. Y. The effect of radical hippocampal ablation on acquisition of avoidance response. Journal of Comparative \& Physiological Psychology, $1961,54,625-628$.

Kimble, D. P. The effects of bilateral hippocampal lesions in rats. Journal of Comparative \& Physiological Psychology, 1963, 56, 273-283.

Means, L. W., Walker, D. W., \& Isaacson, R. L. Facilitated single alternation go, no-go performance following hippocampectomy in the rat. Journal of Comparative \& Physiological Psychology, 1970, 22, 278-285.

Niki, H. The effects of hippocampal ablation on the inhibitory control of operant behavior in the rat. Japanese Psychological Research, 1965, 7, 126-137.

Rabe, A. Discrimination reversal deficit from hippocampal stimulation in the rat. Journal of Psychological Studies, 1963, $14,139-150$.

Raphelson, A. C., Isaacson, R. L., \& Douglas, R. J. The effect of distracting stimuli on the runway performance of limbic damaged rats. Psychonomic Science, 1965, 3, 483-484.

Silveira, J. M., \& Kimble, D. P. Brightness discrimination and reversal in hippocampally lesioned rats. Physiology \& Behavior, 1968, 3, 625-630.

Walker, D. W., Means, L. W. \& Isaacson, R. L. The effects of hippocampal and cortical lesions on single alternation go, no-go acquisition in rats. Psychonomic Science, 1970, 21, 29-31.

Walker, D. W., Messer, L. G., Freund, G., \& Means, L. W. The effect of hippocampal lesions and intertrial interval on single alternation performance in the rat. Journal of Comparative \& Physiological Psychology, 1972, in press.

Wickelgren, W. O., \& Isaacson, R. L. Effects of introduction of an irrelevant stimulus on runway performance of the hippocampectomized rat. Nature, 1963, 200, 48-50.

Woodruff, M. L., \& Isaacson, R. L. Discrimination learning in animals with lesions of hippocampus. Behavioral Biology, 1972, 7, 489-501.

Woodruff, M. L., Schneiderman, B., \& Isaacson, R. L. Impaired acquisition of a simultaneous brightness discrimination by cortically and hippocampally damaged rats. Psychonomic Science, 1972, 27, 269-271.

\section{NOTES}

1. Walker, D. W., \& Means, L. W. The effects of ITI lever availability on go, no-go alternation acquisition in the rat. In preparation.

2. Means, L. W., \& Walker, D. W. Effects of hippocampal lesions on delayed auditory discrimination in the rat. In preparation.

(Received for publication September 26, 1972; accepted October 12, 1972.) 